\title{
A TRAJETÓRIA DO PRONATEC E A REFORMA DO ENSINO MÉDIO: ALGUMAS RELAÇÕES COM A POLÍTICA DE EDUCAÇÃO PROFISSIONAL MUNDIAL1
}

\author{
Danilma de Medeiros Silva² \\ Dante Henrique Moura ${ }^{3}$ \\ Lincoln Moraes de Souza ${ }^{4}$
}

\begin{abstract}
Resumo
As reflexões aqui apresentadas fazem parte das discussões desenvolvidas no âmbito mais geral sobre o Pronatec (Programa Nacional de Acesso ao Ensino Técnico e ao Emprego). Esta atividade contempla várias dissertações e teses e busca compreender o sentido, o papel do Programa e as contradições que se apresentam com a implementação e as transformações no decorrer da sua trajetória. Assim, levantamos que, no atual momento, o Pronatec encontra-se aliado à Reforma do Ensino Médio e em coerência com as políticas de educação profissional a nível mundial. Portanto, evidenciamos uma maior consolidação da dualidade estrutural da educação.
\end{abstract}

Palavras-chaves: Política de educação profissional; Pronatec; Reforma do Ensino Médio.

\begin{abstract}
The reflections presented here are part of the discussions carried out in the more general context about Pronatec (National Program for Access to Technical Education and Employment). This activity contemplates several dissertations and theses and seeks to understand the meaning, the role of the Program and the contradictions that are presented with the implementation and the transformations in the course of its trajectory. Thus, we believe that in the present moment Pronatec is allied to the Reform of the Secondary Education and in coherence with the policies of professional education at world-wide level. Therefore, we show a greater consolidation of the structural duality of education.
\end{abstract}

Keywords: Vocational education policy; Pronatec; Reform of secondary education.

\footnotetext{
${ }^{1}$ DOI: https://doi.org/10.22409/tn.16i30.p10092

${ }^{2}$ Assistente Social do Instituto Federal de Educação, Ciência e Tecnologia do Rio Grande do Norte (IFRN), doutoranda em educação pela Universidade Federal do Rio Grande do Norte (UFRN). E-mail: danilma medeiros@hotmail.com;

${ }^{3}$ Professor do IFRN, coordenou o processo de elaboração da proposta de criação do Programa de Pós-Graduação em Educação Profissional do IFRN - mestrado acadêmico (PPGEP). È Professor colaborador do Programa de Pós-Graduação em Educação (PPGEP) na UFRN, na linha de pesquisa educação, política e práxis educativas. E-mail: dantemoura2014@gmail.com;

${ }^{4}$ Professor da UFRN, do Departamento de Ciências Sociais e do Centro de Ciências Humanas, letras e artes (CCHLA), um dos coordenadores do Grupo de Avaliação de Políticas Públicas (GIAPP) da UFRN. Email: lincolnmoraes03@gmail.com.
} 


\section{Introdução}

O Pronatec foi criado pela Lei $n^{\circ}$ no $12.513 / 2011$ com o intuito, anunciado formalmente, de expandir a oferta de educação profissional e melhorar a qualidade do ensino médio. Apesar de isso aparecer, à primeira vista, uma ação interessante para a democratização da educação profissional brasileira, constatamos que o Programa está mais vinculado ao cumprimento de duas funções necessárias para a manutenção do Estado Capitalista, que são a de acumulação (ligada a manter ou criar as condições para acumulação do capital e para o desenvolvimento das empresas privadas) e de legitimação (voltada para manutenção da chamada harmonia social). Para tanto, fundamentamo-nos em O'Connor (1977).

Para compreendermos o sentido atribuído a essas funções, é importante que situemos rapidamente que a política de educação, assim com as demais políticas públicas, é permeada pelas lutas de classes e por disputas de interesses, como diria Dourado (2011).

A problemática que envolve as discussões diz respeito, em grande parte, à dualidade histórica que marca a política educacional brasileira, considerando que o Estado ofereceu diferentes modelos de educação, a depender do grupo a que se destinou, a saber: formação técnica para os filhos da classe trabalhadora com o intuito de garantir-lhes a sobrevivência e também para o atendimento à urgência do capital por força de trabalho com menor custo e, aos filhos da classe dominante, era-Ihes dada a oportunidade de continuidade dos estudos para posteriormente ocupar os espaços de direção da sociedade. Essa dualidade é uma manifestação inerente ao modo de produção capitalista. Neste sentido, convém destacar a funcionalidade da educação diante do modelo de desenvolvimento econômico (RAMOS, 2004). Além disso, essa dualidade educacional manifestou-se em maior ou menor grau a depender do processo de correlação de forças em disputa.

No que se refere ao aporte teórico-metodológico, temos trabalhado predominantemente com três tipos de literatura. Do ponto de vista do método, fundamentamo-nos em elementos do método dialético marxista. No tocante ao campo de estudo, situamos o Pronatec nas políticas públicas, particularmente na 
política de educação profissional. Por fim, temos utilizado a fundamentação teórica da avaliação de processo de políticas públicas.

Avaliar, segundo o referencial teórico de avaliação de políticas públicas, significa atribuir valor e, com base em Barry e Rae (1975), pode-se dizer que avaliar consiste em dizer se as políticas públicas são boas ou ruins, e, portanto, as avaliações de políticas e programas respondem geralmente a objetivos distintos, como podemos encontrar em Weiss (1978) e em Draibe (2001). Comumente registram-se, na literatura que trata de avaliação de políticas públicas, as seguintes modalidades de avaliação: a avaliação política, a avaliação de processo, a avaliação de impacto e a meta-avaliação.

Sobre a avaliação política de políticas públicas, afirmamos, com base em Figueiredo e Figueiredo (1986), que esse tipo de avaliação pode ser considerada como um outro momento das demais avaliações e, no caso do nosso objeto de estudo, que é o Pronatec, realizamos uma avaliação política do Programa (SILVA, 2015). Nessa avaliação, no fundamental, apontamos a sua ideologia, as suas teorias e os seus objetivos explícitos e implícitos, seguindo o enfoque metodológico desenvolvido por Souza (2014). Assim foi possível constatar que o Programa contribui para o cumprimento das funções de legitimação e acumulação, como explicitamos anteriormente.

A partir da avaliação política do Pronatec, elucidamos a necessidade de desenvolver uma avaliação da implementação do referido Programa, como forma de continuidade da investigação, considerando que a avaliação de processo possibilita aferir se o programa está sendo (ou foi) implementado de acordo com as diretrizes concebidas para a sua execução e se tem atendido as metas oficialmente desejadas ou explicitadas nos documentos governamentais.

Draibe (2001), assim como outros autores, traz elementos metodológicos importantes para avaliação de processo, por meio dos quais temos direcionado a pesquisa para a trajetória de implementação do Pronatec. Esta mesma autora também expõe que, na avaliação de processo, a questão norteadora está baseada nos condicionamentos que levam a êxito ou a fracasso de determinada política pública ou programa.

Para Costa e Castanhar (2003), a aplicação da avaliação de processo requer os desenhos dos fluxos e processos de programa, o que nos remete a 
pensarmos na trajetória de implementação do Pronatec. Esses autores citam Scheirer (1994) para colocar que a avaliação de processo "pode ser definida como a maneira de identificar o verdadeiro conteúdo de um programa público, se ele está sendo realizado como previsto" (SCHEIRER, 1994, p. 983). Também, com base na mesma autora, afirmam a necessidade de, na avaliação de processo, desenvolverem-se métodos para buscar os motivos de existirem diferenças entre os objetivos (e intenções) do programa e os que são realmente realizados.

Figueiredo e Figueiredo (1986), por sua vez, direcionam a avaliação de processo para aferição da eficácia que está diretamente ligada ao alcance das metas. Apresentam o conceito de eficácia objetiva que, para eles, diz respeito a avaliar "se as metas atingidas são iguais, superiores ou inferiores às metas propostas", (FIGUEIREDO E FIGUEIREDO, 1986, p. 112). É importante também destacarmos que, nesse mesmo texto, os autores discutem a avaliação política de políticas públicas sob "a análise e elucidação do critério ou critérios que fundamentam determinada política: as razões que a tornam preferível a qualquer outra" (p. 108). Assim, ao estarmos desenvolvendo uma avaliação de processo do Pronatec, por meio da avaliação política que realizamos, nos coloca para avaliarmos as metas do Programa com base nos seus objetivos não só explícitos, mas principalmente implícitos.

Por meio dessas questões, consideramos, inicialmente, que a trajetória do Pronatec tem se dado em três momentos. O primeiro, que vai da criação do programa em 2011 às eleições presidenciais de 2014, em que se destaca a contribuição para cumprimento da função de legitimação do Estado Capitalista por meio dos cursos de Formação Inicial e Continuada de Trabalhadores (FIC); o segundo, registrado após a reeleição da Presidenta Dilma até o momento do impeachment (2015-2016), em que se registra um declínio na oferta do Programa; e o terceiro momento, de 2017 em diante, com ênfase para Reforma do ensino médio e oferta do Mediotec (cursos técnicos) como base de

\footnotetext{
${ }^{4}$ Sobre o impeachment da Presidenta Dilma ressaltamos que esse processo foi "conturbado e carregado de dúvidas sobre sua legalidade e legitimidade que o levou a ser chamado de golpe", como destacam Ferreti e Silva (2017, p. 386). Sobre o golpe, Moura e Lima Filho (2017) discutem que o impeachment de Dilma fez parte de um contexto mais amplo de "radicalização do neoliberalismo, que visa perpetrar um golpe contra a classe trabalhadora mais pobre do País" (p.111).
} 
implementação da Reforma, em que é possível pressupor uma maior contribuição para função de acumulação do Estado Capitalista.

Sobre a chamada Reforma do Ensino Médio, esse processo esteve em curso pouco tempo depois da criação do Pronatec, quando foi montada, na Câmara dos Deputados, em 2012, uma Comissão Especial destinada a promover estudos sobre a Reformulação do Ensino médio (CEENSI). A CEENSI apresentou o Projeto de Lei (PL) 6840/2013, propondo alterações na Lei de Diretrizes e Bases da Educação (Lei no 9394/1996), principalmente no que diz respeito ao ensino Médio. Esse PL sofreu várias críticas de estudiosos da área da educação e também dos movimentos sociais que defendem uma educação pública e de qualidade social referenciada. Todavia o processo de aprovação dessa reforma foi aligeirada após o impeachment da Presidente Dilma, pois, antes mesmo de completar um mês da posse do Presidente Michel Temer, ele emitiu a Medida Provisória (MP) 746, que aprovou tal reformulação de maneira autoritária ${ }^{5}$ e que, logo após, transformou-se na Lei n 13.415/2016.

Como forma de uma melhor compreensão sobre a temática em tela, apresentaremos alguns pontos gerais sobre as transformações do capitalismo, para, a partir daí, discutir sobre alguns elementos que configuram a política de educação profissional mundial. Com base nisso, refletiremos sobre os fundamentos do Pronatec e os seus possíveis vínculos com a Reforma do Ensino Médio, sobretudo no momento atual de oferta do Programa. As análises aqui apresentadas, como já ressaltamos, ainda são preliminares e fazem parte das discussões sobre o tema.

\section{Configuração da política da educação profissional no plano internacional no contexto da implementação do Pronatec: breves análises}

No sentido de avaliarmos o Pronatec, é importante não perdermos de vista alguns aspectos que envolvem a macropolítica do desenvolvimento do capitalismo e questões que pressupomos estar na base da existência do Programa e nas suas diferenças e semelhanças com ações da educação profissional de outros países e que vinculam a existência do Programa com a

\footnotetext{
${ }^{5}$ Isso por ter instituído as alterações via Medida Provisória, instrumento incomum na Política de Educação até na Ditadura Militar.
} 
Reforma do Ensino Médio, ao passo que a política de educação recebe orientação dos chamados organismos internacionais (CEPAL, Banco Mundial, UNESCO, entre outros).

No que toca aos aspectos de transformações do capitalismo, no contexto neoliberal, os que mais se vinculam com o nosso tema são os seguintes:

- Assiste-se a uma generalização mais intensiva e extensiva da mercadorização, ou seja, amplia-se, com uma grande velocidade e em maiores áreas e espaços, a transformação crescente das atividades e outras dimensões da vida em mercadoria. O meio ambiente, a saúde, o lazer e a educação, por exemplo, passam simplesmente a ser considerados como algo a ser vendido e comprado, seja diretamente ou travestido de serviços direcionados a clientes e consumidores.

- Como base ideológica das mudanças do capitalismo atual, o neoliberalismo passa a ser predominante, inclusive esvaziando e subordinando outras ideologias anteriormente dominantes, como o antigo conservadorismo, a centralidade na família e outras. $O$ individualismo levado a extremo, o mercado capitalista como instância central e o Estado máximo para os dominantes e mínimo para as classes populares passam a ser o núcleo ideológico por excelência.

- A dimensão pública é cada vez mais esvaziada e divulgada como uma coisa desprovida de importância ou carente de sentido para a vida. O que é público é considerado como algo inferior ou mesmo prejudicial e não moderno, como se a negatividade fosse uma característica intrínseca do espaço público, e a dimensão privada, especialmente das atividades econômicas, trouxesse no seu bojo o melhor da vida.

- A dimensão econômica ou economicismo assume ares de referência central da vida, e mesmo a política, a economia, a cultura e outros níveis de nossa existência passam a ser vistos por meio da lente da economia capitalista e de seu mercado.

- A ciência integra-se cada vez mais com a atividade econômica e com o capital. Neste sentido, o conhecimento torna-se cada vez mais um elemento do processo produtivo ou da circulação de mercadorias e consumo. Daí, a educação vai perdendo sua condição de transmissão de conhecimento ou direito da 
população e é rebaixada, em muitos casos, a uma mera transmissão de informações aligeiradas e de aplicação parcial e imediata ou diluída na chamada capacitação ou treinamento.

- O Estado reduz sua centralidade no plano nacional, dilui-se em parte no plano local e é localizado progressivamente no circuito mais amplo da internacionalização do capital. É como se estivesse sendo produzido um Estado supranacional do capital (SOUZA; 2015), hegemonizado pelos Estados Unidos e formado por vários aparelhos estatais como o Banco Mundial, o BID, a OMC, a ONU entre outros, chamados candidamente de agências internacionais.

Além dessas questões, é imprescindível atentarmos para o que autores, a exemplo de Chesnais (1996), conceituam como mundialização do capital e outros autores conceituam como globalização, a exemplo de Jameson (2001).

De maneira mais geral, a mundialização do capital diz respeito à internacionalizaçãodo capital que corresponde à intensificação do desenvolvimento do capitalismo e apresenta características próprias e

particulares em relação aos outros momentos. Não é forçoso situarmos rapidamente, a partir dos escritos de Chesnais (1996), que esse processo é marcado pela crise dos anos de 1970, quando as instâncias políticas dos Estados capitalistas mais poderosos adotam uma série de medidas que contribuíram para a mundialização do capital. O autor destaca, portanto, a ofensiva do capital na

produção (a reestruturação produtiva) e da ofensiva do capital na política (o neoliberalismo) como elementos centrais que marcam a mundialização do capital.

É igualmente importante apreendermos que a chamada mundialização do capital não se caracteriza pela mundialização das trocas de mercadorias e serviços, conforme Chesnais (1996) destaca ao afirmar que, nos anos de 1980 e

1990, houve um crescimento bastante inferior aos dos anos de 1960 e 1974, diante da mundialização das operações do capital.

Esse aspecto pode ser mais bem compreendido a partir do que Jameson (2001) expõe sobre a globalização, enfatizando a necessidade de compreensão para além do nível econômico, e apresenta outros níveis igualmente importantes, a saber: tecnológico, político, cultural e social. Isso remete para as influências culturais, sociais e políticas de países hegemônicos sobre os chamados países subdesenvolvidos e a forma como os organismos internacionais, a exemplo da 
CEPAL, Banco Mundial, UNESCO, entre outros, financiam e ditam a política de educação.

Nesse mesmo sentido, em Harvey (1993), podemos refletir sobre os modos de produção capitalista que deram sustentabilidade às formas de pensar e agir das sociedades submetidas ao capitalismo e como a política de educação esteve e ainda está correlacionada aos modos de produção.

A título de ilustração, entretanto de maneira superficial e espelhando-nos em Harvey (1993), podemos dizer que no Fordismo e Taylorismo o formato de profissional exigido teve por base a produção rígida, produção em massa e controlada que impôs um modelo de educação voltada para técnica, em que se aprendia um ofício e o trabalhador, ao longo da sua vida, desempenhava a mesma função.

Em tempos de reestruturação produtiva, o Toyotismo intensifica as relações de produção e a base passa a ser o profissional polivalente, agregando conhecimentos em outros serviços e remodelando a estrutura das empresas através das técnicas organizacionais. Nessa ordem, os chamados avanços tecnológicos e as interações entre diversos países com a mundialização do capital são as principais estratégias de reprodução do capitalismo.

No contexto da reestruturação produtiva, Araújo (1999, p.19) assinala que o perfil exigido dos trabalhadores centra-se em exigências baseadas em um leque de características pessoais:

iniciativa, espírito de equipe, capacidade de comunicação, sociabilidade, criatividade, disposição para aprender, curiosidade, disciplina, motivação, atenção, responsabilidade, estabilidade, confiança, autonomia, capacidade de cooperação, lealdade, comprometimento, competitividade, habilidade de negociação, capacidade de pensar, de decidir etc.

Além disso, Araújo (1999) aponta que em cada contexto histórico, e cada forma de organização da produção, foram exigidos modos específicos de se colocar diante da produção da vida. Entretanto, no contexto da reestruturação produtiva - toyotista - as "características pessoais" exigidas dos trabalhadores sofrem uma readequação, para se manterem funcionais à lógica do capital. 
Sobre essas questões Gamboa (2001) apresenta que é preciso driblar os desafios da reestruturação produtiva em que o avanço da tecnologia tem feito surgir novas problemáticas para educação, sem que se tenha vencido as demandas mais elementares de acesso da população à leitura e à escrita. Assim, o autor propõe um olhar crítico para desmascarar o projeto da chamada sociedade global e das relações que o capital impõe para educação.

$\mathrm{Na}$ verdade, a educação, ao invés de uma atividade ligada à produção e difusão do conhecimento, baseada em valores de ordem moral e ética ou um direito a que toda a população pudesse ter acesso, vai ser rebaixada a uma atividade como outra qualquer e susceptível de ser vendida e comprada no mercado capitalista. Na linguagem mais em voga na visão capitalista, deve ser considerada como um simples serviço que uma parte (Estado ou empresas privadas) oferecem aos clientes ou consumidores ou consumidoras. Não por acaso, vai ser no centro do capitalismo, no caso os Estados Unidos, que esta mudança vai assumir ares de normalidade e de natural e de atividades supostamente novas e originais como mostra Ravitch (2011) de modo crítico.

Para ampliarmos a nossa compreensão sobre esse processo, no contexto atual, elaboramos o quadro a seguir com as principais características da educação profissional em alguns países: Estados Unidos, Japão, Alemanha, Inglaterra, França (que fazem parte do chamado G7) ${ }^{6}$ e o Brasil.

Nesse intuito, e para desvelarmos o real sentido posto para a educação profissional no mundo globalizado, parafraseando Gamboa (2001), tomamos por referência um documento elaborado pelo Serviço Nacional de Aprendizagem Industrial (Senai) em 2015, intitulado por "Panorama Mundial da educação profissional: desafios e respostas"7. Também, evidenciamos a realidade portuguesa, por termos dados empíricos da realidade desse país ${ }^{8}$, deixando claro

\footnotetext{
${ }^{6}$ O G7 é composto pela Alemanha, Canadá, Estados Unidos, França, Itália, Japão e Reino Unido. Esses países são considerados as sete economias mais avançadas do mundo de acordo com o Fundo Monetário Internacional (FMI). No entanto a União Europeia também está representada no G7. Da União Européia nos debruçamos acerca do Ensino Profissional Português.

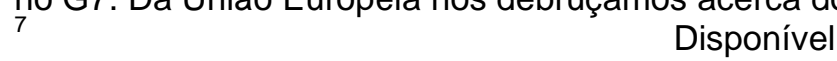

http://tracegp.senai.br/bitstream/uniepro/190/1/Panorama\%20Mundial\%20da\%20Educaca0\%20Pr ofissional SENAI.pdf, acesso em 18 de setembro de 2017.

${ }^{8}$ Danilma de Medeiros Silva realizou Estágio Científico Avançado de Doutoramento, na Universidade do Minho, em Portugal, Instituto de Educação, Departamento de Ciências Sociais da Educação, na especialidade de Política Educativa, com financiamento da Capes, pelo Programa de Doutorado Sanduíche (PDSE), de abril a julho de 2017.
} 
que não objetivamos tecer comparações sistemáticas entre realidades distintas, mas, sim, analisarmos os aspectos mais gerais que talvez estejam na base da mundialização do capital.

Quadro 1: A configuração da educação profissional em alguns países

\begin{tabular}{|c|c|c|}
\hline Países & $\begin{array}{ll}\text { Alguns } & \text { destaques } \\
\text { históricos } & \end{array}$ & Atual configuração \\
\hline Estados Unidos & $\begin{array}{l}\text { Tradição de promover a } \\
\text { educação profissional desde } 0 \\
\text { século XIX; }\end{array}$ & $\begin{array}{l}\text { - Coexistem três "escolas", a } \\
\text { acadêmica, preparatória para o nível } \\
\text { superior; a vocacional, que também } \\
\text { dá acesso aos estudos superiores, } \\
\text { porém, pela è ênfase à } \\
\text { profissionalização, proporciona aos } \\
\text { alunos condições acadêmicas } \\
\text { inferiores à da primeira, e a geral, que } \\
\text { tende a reunir os alunos de menor } \\
\text { aproveitamento em torno de currículos } \\
\text { menos exigentes; } \\
\text { - O país facilita a conclusão do ensino } \\
\text { secundário, buscando assegurar a } \\
\text { todos a escolarização universal até ao } \\
\text { décimo segundo ano, sendo uma } \\
\text { condição essencial para a } \\
\text { empregabilidade. }\end{array}$ \\
\hline Alemanha & $\begin{array}{l}\text { Sistema dual, com inspiração } \\
\text { das guildas medievais, } \\
\text { corporações de ofício dos } \\
\text { artesãos e artistas; }\end{array}$ & $\begin{array}{l}\text { - O sistema dual da Alemanha baseia- } \\
\text { se na separação cedo dos que vão } \\
\text { para os estudos superiores (entre } 11 \text { e } \\
12 \text { anos) e a profissionalização; } \\
\text { - Apesar disso, destaca-se um certo } \\
\text { prestígio para educação profissional, } \\
\text { ao passo que há ocorrência de } \\
\text { transferências de retorno, pelas quais } \\
\text { alunos de nível superior matriculam-se } \\
\text { em cursos técnicos para melhor } \\
\text { construir as pontes entre teorias e } \\
\text { práticas e entre a formação e o } \\
\text { trabalho; } \\
\text {-Estabeleceram-se possibilidades } \\
\text { para que o egresso da educação } \\
\text { profissional, prossiga os seus estudos } \\
\text { na educação superior, que é } \\
\text { diversificada e flexível, composta de } \\
\text { universidades, escolas politécnicas, } \\
\text { universidades tecnológicas e } \\
\text { faculdades profissionais. Todavia, os } \\
\text { egressos dos cursos acadêmicos ou } \\
\text { de educação geral, possuem uma } \\
\text { formação superior com maior } \\
\text { amplitude. }\end{array}$ \\
\hline Japão & $\begin{array}{l}\text { Tradição de preparo escolar, } \\
\text { forte influência estatal e } \\
\text { modesta procura pela educação } \\
\text { profissional (separação entre } \\
\text { trabalho e educação?); }\end{array}$ & $\begin{array}{l}\text { - A educação e treinamento estão em } \\
\text { grande parte separados, a primeira no } \\
\text { Ministério da Educação e o último no } \\
\text { Ministério do Trabalho. }\end{array}$ \\
\hline
\end{tabular}




\begin{tabular}{|c|c|c|}
\hline França & $\begin{array}{l}\text { - Desenvolveu uma das } \\
\text { matrizes históricas da educação } \\
\text { profissional, que teve amplas } \\
\text { repercussões no mundo, } \\
\text { inclusive no Brasil. } \\
\text { Este modelo é centralizado, } \\
\text { estatal e incorporado ao sistema } \\
\text { educacional, com raízes nas } \\
\text { reformas napoleônicas e outras. }\end{array}$ & $\begin{array}{l}\text { - A escola única vai até os } 14 \text { anos de } \\
\text { idade e, dos } 15 \text { aos } 18 \text { anos, se } \\
\text { estende à educação secundária } \\
\text { superior, com várias opções de } \\
\text { educação geral e profissional, } \\
\text { culminando com um exame de } \\
\text { conclusão; } \\
\text { - Aproximadamente } 37 \% \text { dos alunos } \\
\text { da educação secundária inferior } \\
\text { matriculam-se numa opção } \\
\text { profissional, como resultado de um } \\
\text { processo de orientação em que a } \\
\text { escolha do aluno e da família tende a } \\
\text { alcançar menor importância do que o } \\
\text { desempenho do aluno na escola e a } \\
\text { decisão dos orientadores; } \\
\text { - Nesse sentido, como em outros } \\
\text { países, a orientação educacional é } \\
\text { acusada de ser um processo mais ou } \\
\text { menos suave de seleção escolar e } \\
\text { social, que reflete a forte influência } \\
\text { das origens sociais dos alunos. Os } \\
\text { estudantes e os pais podem optar, } \\
\text { mas o ingresso é determinado pela } \\
\text { escola, em vista do desempenho e } \\
\text { outras características. }\end{array}$ \\
\hline $\begin{array}{l}\text { Reino Unido: Foco } \\
\text { na Inglaterra }\end{array}$ & $\begin{array}{l}\text { - Defrontado com os desafios da } \\
\text { economia globalizada e da } \\
\text { competitividade, o Reino Unido } \\
\text { e, em particular, a Inglaterra } \\
\text { deram grandes passos para a } \\
\text { melhoria da educação } \\
\text { profissional desde os anos } \\
1980 .\end{array}$ & $\begin{array}{l}\text { - Sistema flexível, de quase mercado, } \\
\text { com menor participação do Estado; } \\
\text { - Processos de avaliação exigentes, } \\
\text { oferecendo dados e informações para } \\
\text { aumentar o conhecimento do público } \\
\text { sobre as opções. }\end{array}$ \\
\hline Brasil & $\begin{array}{l}\text { - A educação e a formação } \\
\text { profissional no Brasil têm duas } \\
\text { fontes: a escolar pública } \\
\text { francesa, cuja semente está nas } \\
\text { escolas de aprendizes do início } \\
\text { do século XX, e a educação não } \\
\text { formal, representada } \\
\text { majoritariamente pelos sistemas } \\
\text { paraestatais, criados a partir da } \\
\text { Segunda Guerra Mundial } \\
\text { (Sistema S). }\end{array}$ & $\begin{array}{l}\text { Em } 2011 \text { se estabeleceu marco } \\
\text { significativo: foi criado o Programa } \\
\text { Nacional de Acesso ao Ensino } \\
\text { Técnico e Emprego - PRONATEC, } \\
\text { com recursos do MEC, Fundo de } \\
\text { Amparo ao Trabalhador, BNDES e } \\
\text { outros; }\end{array}$ \\
\hline
\end{tabular}

Fonte: Elaborado pelos autores a partir do documento do SENAI de 2015, intitulado por "Panorama Mundial da educação profissional: desafios e respostas".

Conforme o que consta no documento do SENAI e foi apresentado no quadro acima, elencamos que, no geral, a educação profissional nesses países apresenta os seguintes aspectos: dualidade educacional, sistema flexível de quase mercado, direcionamento para educação profissional a partir da classe social, educação profissional como acesso para empregabilidade. Tais aspectos 
nos remetem à própria organização do modo de produção capitalista, no que concerne à divisão social de trabalho, que cinde a sociedade entre ocupações, cada qual apropriada a certo ramo de produção (BRAVERMAN,1977).

Além disso, é importante ressaltar que a divisão do trabalho, com a intensificação do capitalismo, também fica explícita fora das unidades de produção, por meio da forma como os processos de qualificação da força de trabalho acontecem ao passo que se são ofertados modelos de qualificação que direcionarão os que irão ocupar os trabalhos manuais e os trabalhos intelectuais. E a educação profissional, como se configura nos países apresentados no quadro, geralmente assume uma qualificação voltada para os mais pobres.

Nesse sentido, é importante nos voltarmos ao que apresenta Braverman (1977) ao dizer que é indesejável para o capitalista a distribuição generalizada do conhecimento do processo produtivo. Por esta razão, a base da dualidade educacional é necessária para manutenção do sistema capitalista.

Sobre a realidade do ensino profissional português, foi possível observar a presença marcante da separação entre educação propedêutica e educação profissional, e historicamente esta última foi destinada aos estudantes com insucesso escolar. Por isso, prevalece um estigma em relação aos cursos profissionais, mesmo havendo uma ampliação das instituições que ofertam esses cursos de 1994 em diante, quando outrora os cursos profissionais eram ofertados apenas pelas chamadas escolas profissionais. Nos últimos anos, o governo português tem aumentado substancialmente a oferta de educação profissional, o que, para alguns estudiosos, esse processo é entendido como se o ensino profissional houvesse saído da "periferia para o centro" da política de educação (Azevedo, 2014) voltada para formação do ensino secundário dos adolescentes (nosso ensino médio aqui no Brasil). Entretanto, os cursos profissionais possuem procura menor do que os cursos científicos e ainda são vistos como cursos voltados para estudantes com insucesso escolar. Por outro lado, mesmo com a baixa procura por esses cursos, o Estado português sinaliza aumentar a oferta de educação profissional.

No que se refere à continuidade dos estudos, há pouca inserção dos estudantes advindos dos cursos profissionais portugueses no ensino superior: "[...] Em 2014/15, 79\% dos que concluíram os cursos gerais ingressaram no 
ensino superior. No caso dos cursos profissionais, foram $14,6 \%$, sendo que apenas $5 \%$ entraram numa licenciatura. Os restantes inscreveram-se em Cursos de Especialização Tecnológica, entretanto substituídos pelos Cursos Técnicos Superiores Profissionais. Apesar de serem dados em institutos politécnicos, não dão direito a grau académico, ainda que permitam depois a transição para uma licenciatura". (notícia apresentada no Jornal Expresso, em 03/06/2017, p. 19).

Essas questões, que apresentamos sobre exemplos da política de educação nos países citados, ajudam-nos a refletir sobre o contexto da política de educação profissional brasileira, no sentido de que a expressa dualidade entre educação profissional e educação propedêutica é acentuada com a implementação do Pronatec e será reforçada ainda mais com a Reforma do Ensino Médio, aprovada pela Lei Federal oํ 13.415, de 16 de fevereiro de 2017.

Tal reforma reproduz o formato do ensino secundário implementado em Portugal e em outros países europeus, a exemplo da França, porém as condições socioeconômicas do Brasil estabelecem um contexto ainda mais perverso aos estudantes inseridos no ensino profissional exclusivamente técnico.

No próximo tópico, procuramos refletir sobre os fundamentos do Pronatec e as vinculações com a Reforma do Ensino Médio, ao elencar os aspectos na trajetória do Programa que tem contribuído para dualidade educacional e para o cumprimento das funções de legitimação e acumulação do Estado Capitalista.

\section{Os fundamentos do Pronatec e a sua trajetória: dados exploratórios que vinculam o momento atual do Programa à reforma do ensino médio}

Passados 6 anos da criação do Pronatec, é possível observar os diversos momentos vivenciados a partir da trajetória do Programa. No geral, pressupomos que o Programa pode ser situado em três momentos históricos, como apresentamos na introdução desse texto.

A ideia de trajetória, que temos adotado para avaliar a implementação do Pronatec, parte do que foi teorizado por Bourdieu (1996), em seu texto intitulado "A llusão Biográfica" e que é aplicado pelo grupo de avaliação de Políticas Públicas da Universidade Federal do Ceará (UFC). E, como já explicitamos, nosso aporte teórico tem amparo nos escritos de Costa e Castanhar (2003), Draibe (2001), Scheirer (1994), Figueiredo e Figueiredo (1986), entre outros. 
Nessa linha de pensamento, é que não buscamos interpretar a trajetória do Pronatec como um conjunto coerente, mas como algo que se desloca no espaço social (BOURDIEU, 1996), que nosso entendimento, com base no método dialético, tem variações a partir de cada contexto social e político, e, portanto, é repleto de contradições. Assim, a trajetória atravessa diversos momentos (não etapas ou fases) e requer critérios e parâmetros metodológicos para definição dos momentos históricos, sendo o passo inicial desses parâmetros os fundamentos do Pronatec, na busca de identificar o seu verdadeiro conteúdo e confrontar se o Programa está sendo realizado como previsto (Scheirer 1994).

Por isto, é importante discutir sobre a trajetória do Pronatec e trazer reflexões sobre as vinculações do Programa com o contexto da chamada reforma do ensino médio, para explicitarmos, por meio dos fundamentos expressos nas legislações, como esse caminho vem sendo construído.

A lei criadora do Pronatec, Lei $n^{\circ} 12.513 / 2011$, no seu artigo $1^{\circ}$, estabeleceu como objetivos, entre outros: "expandir, interiorizar e democratizar a oferta de cursos de educação profissional técnica de nível médio presencial e a distância e de cursos e programas de formação inicial e continuada ou qualificação profissional; Contribuir para a melhoria da qualidade do ensino médio público, por meio da articulação com a educação profissional; estimular a articulação entre a política de educação profissional e tecnológica e as políticas de geração de trabalho, emprego e renda" .

É possível observar, considerando esses objetivos, a relação direta do Pronatec com o ensino médio público, a partir da oferta por meio de cursos concomitantes. Vejamos como foram declaradas as modalidades do Pronatec:

Art. $5^{\circ}$ Para os fins desta Lei, são consideradas modalidades de educação profissional e tecnológica os cursos:

I - de formação inicial e continuada ou qualificação profissional; e

II - de educação profissional técnica de nível médio; e

III - de formação de professores em nível médio na modalidade normal.

$\S 1^{\circ}$ Os cursos referidos no inciso I serão relacionados pelo Ministério da Educação, devendo contar com carga horária mínima de 160 (cento e sessenta) horas.

$\S 2^{\circ}$ Os cursos referidos no inciso II submetem-se às diretrizes curriculares nacionais definidas pelo Conselho Nacional de Educação, bem como às demais condições estabelecidas na legislação aplicável, devendo constar do Catálogo Nacional de 
Cursos Técnicos, organizado pelo Ministério da Educação (BRASIL, 2011, n.p.).

A meta que foi anunciada para implementação desses cursos, logo após a criação do Programa, foi de formar mais de 8 milhões de brasileiros, no período de 2011 a 2014. À primeira vista, essa meta pode apresentar-se como uma perspectiva muito interessante de possibilitar o acesso da população brasileira à qualificação profissional, todavia o que precisa ser refletido é o significado de se oferecer cursos FIC de 160 e técnicos concomitantes, ao invés de se ampliar o acesso à educação profissional integrada à educação propedêutica. Cabe aqui amparar-nos em Barry e Rae (1975), ao exporem que, na avaliação de uma política pública ou, no caso Programa, deve-se voltar para análise de se questionar a intenção de uma política ser preferível à outra.

Conforme apresentamos na introdução, a política de educação profissional no Brasil esteve, ao longo dos anos, permeada por dois projetos em disputas, como enfatiza Ramos (2004), sendo um voltado a um modelo de educação baseado na formação técnica para os filhos da classe trabalhadora, outro de formação propedêutica para os filhos das elites brasileira e outro defendido pelos movimentos sociais por uma educação pública, cuja formação deve integrar trabalho, ciência, tecnologia e cultura. No Governo Lula, com a revogação do

Decreto 2.208/97 (esse Decreto proibia terminantemente a integração entre educação propedêutica e educação profissional), houve alguns avanços numa declarada intenção em se construir uma política de educação profissional que atendesse em alguma medida as reivindicações históricas da classe trabalhadora.

Apresentamos que o Pronatec, ao propor os cursos FIC e o médio técnico concomitantemente, explicitamente figura-se como um Programa que mostra, como fundamentação, o oferecimento de formação meramente técnica para a classe trabalhadora. Com isso, reafirma a dualidade estrutural, tendo em vista que se direciona a formação técnica aos filhos da classe trabalhadora e aos sujeitos que vivenciam situações de vulnerabilidade social, que é parte integrante do processo de exploração capitalista. Vejamos a quem se destina o programa:

Art. $2^{\circ} \mathrm{O}$ Pronatec atenderá prioritariamente:

I - estudantes do ensino médio da rede pública, inclusive da educação de jovens e adultos; 
II - trabalhadores;

III - beneficiários dos programas federais de transferência de renda; e

IV - estudante que tenha cursado o ensino médio completo em escola da rede pública ou em instituições privadas na condição de bolsista integral, nos termos do regulamento (BRASIL, 2011, n.p.).

Ao se voltar a atender prioritariamente estudantes da rede pública de ensino, trabalhadores e beneficiários dos programas federais de transferência de renda, o Pronatec assume o que foi posto ao longo da história da educação brasileira: educação técnico-instrumental destinada à classe trabalhadora, cujo discurso principal é "atender as demandas do setor produtivo". Dessa maneira, o Pronatec caminha na contramão da perspectiva de formação politécnica.

Em relação à oferta do Pronatec, os cursos técnicos, na forma concomitante, estão ligados à bolsa-formação estudante ${ }^{9}$ e os cursos FIC estão relacionados à bolsa-formação trabalhador e apresentam como características e objetivos:

Art. 17. São objetivos e características da Bolsa-Formação Estudante:

I - formar profissionais para atender às demandas do setor produtivo e do desenvolvimento socioeconômico e ambiental do País;

II - contribuir para a melhoria da qualidade do ensino médio público, por meio da articulação com a educação profissional; e III - ampliar e diversificar as oportunidades educacionais aos estudantes, por meio do incremento da formação técnica de nível médio.

[...]

Art. 38. São objetivos e características da Bolsa-Formação Trabalhador:

I - formar profissionais para atender às demandas do setor produtivo e do desenvolvimento socioeconômico e ambiental do País;

II - ampliar as oportunidades educacionais por meio da educação profissional e tecnológica com a oferta de cursos de formação profissional inicial e continuada;

III - incentivar a elevação de escolaridade; e

IV - integrar ações entre órgãos e entidades da administração pública federal e entes federados para a ampliação da educação profissional e tecnológica [...] (MEC, 2013, n.p., grifos nossos).

\footnotetext{
${ }^{9}$ Tanto a bolsa- formação estudante quanto a bolsa-formação trabalhador foi a forma encontrada pelo Governo para repasse de recursos financeiros do Programa a própria Rede de Educação profissional e tecnológica, como principalmente a manobra jurídica para destinação de verbas públicas para o Sistema $\mathrm{S}$ e demais empresas privadas.
} 
No que se refere aos objetivos expostos no documento citado (Portaria $\mathrm{n}^{\circ}$ 168/2013), fica claro que a intenção declarada do Pronatec é "formar profissionais para atender às demandas do chamado setor produtivo e do desenvolvimento socioeconômico e ambiental do País". Este objetivo aparece tanto na bolsaformação estudante (cursos técnicos) como na bolsa-formação trabalhador (cursos FIC). Isso também foi posto no documento que enviou o Projeto de Lei do Pronatec à Presidência da República, justificando-se com o chamado "apagão de mão de obra". Vale relembrar que essa ligação que se propaga da educação com o desenvolvimento econômico segue uma tendência mundial, como apontamos anteriormente.

Em relação à formação, para o atendimento das demandas do setor produtivo por meio dos cursos FIC, com carga horária de 160 horas, como se propõe o Pronatec na Bolsa-formação trabalhador, é pertinente atentar que esses cursos, na maioria das vezes, não formam para o mercado de trabalho. Pesquisa realizada pela Fundação Getúlio Vargas $(\mathrm{FGV}-2010)^{10}$, realizada em 2010, demonstra que a incidência dos cursos $\mathrm{FIC}^{11}$, para inserção no mercado de trabalho, fica bastante aquém, em comparação com os cursos técnicos de nível médio e principalmente no que se refere aos cursos superiores.

Moura (2012), ao analisar o Pronatec, faz referência aos estudos da FGV e afirma que a pesquisa, por mais que tenha sido patrocinada para atender aos interesses dos capitalistas, põe em evidência que a execução dos cursos de curta duração no Pronatec volta-se para "contenção social por meio do qual proporciona educação pobre para os pobres" (MOURA, 2012, p. 26). Assim, é que vinculamos a oferta dos cursos FIC mais diretamente à contribuição do cumprimento da função de legitimação do Estado capitalista.

Outro objetivo levantado para a Bolsa-formação Estudante foi o de "contribuir para a melhoria da qualidade do ensino médio público, por meio da articulação com a educação profissional" (MEC, Portaria 168, art. 17, inciso II).

Refletindo sobre essa pretensa perspectiva de melhoria da qualidade do ensino médio público, por meio do Pronatec com os cursos técnicos concomitantes, é que percebemos vinculações direta dessa oferta com o que foi

\footnotetext{
${ }^{10}$ Disponível em: http://cps.fgv.br/VOT2, acesso em: setembro de 2014.

${ }^{11}$ Qualificação profissional é o termo utilizado na pesquisa para os cursos FIC.
} 
posto na Lei № 13.415 , de 16 de fevereiro de 2017, que reformulou o ensino médio brasileiro. Além disso, também compreendemos que o formato traçado para a política de educação, tanto com o Pronatec como com a Reforma do Ensino Médio, atende prontamente ao contexto mundial de mercadorização da educação e de fragmentação do conhecimento. Percebe-se que a política de educação é organizada para atender os processos de reprodução do sistema capitalista, dentro da lógica da divisão social do trabalho.

Nessa linha de reflexão, Kuenzer (2005) argumenta que, para reprodução do capital, é necessário que a força de trabalho esteja qualificada de forma desigual para ocupação dos postos de trabalho, enfatizando-se, portanto, o papel fundamental dos cursos de baixa qualificação.

Os fundamentos da Lei № 13.415/2017, que reformulou o ensino médio, retomam claramente a separação entre educação propedêutica e educação profissional. Isso porque fragmenta o ensino médio por área de conhecimento por meio de cinco arranjos curriculares que são: I - linguagens e suas tecnologias; II matemática e suas tecnologias; III - ciências da natureza e suas tecnologias; IV ciências humanas e sociais aplicadas; $\mathrm{V}$ - formação técnica e profissional.

Convém apresentar que essa Lei alterou não apenas artigos da LDB (Lei de Diretrizes e Bases da Educação), mas também da CLT (Consolidação das Leis do Trabalho), do FUNDEB (Fundo de Manutenção e Desenvolvimento da Educação Básica e de Valorização dos Profissionais da Educação), revogou uma lei que tornava obrigatório o ensino do Espanhol e instituiu a Política de Fomento à Implementação de Escolas de Ensino Médio em Tempo Integral.

Uma das justificativas apresentada para o Governo Temer instituir a Reforma do Ensino médio, por meio da Medida Provisória (MP 746/2016), instrumento incomum na Política de Educação até na Ditadura Militar, foi a de possibilitar a flexibilização do currículo, a partir da suposta escolha dos estudantes do seu itinerário acadêmico (frente às cinco áreas dos arranjos curriculares). Entretanto a própria Lei № 13.415/2017, no seu artigo 4을 estabelece que a organização das áreas de conhecimento ficará a cargo de cada sistema de ensino. Isso quer dizer que nem todos os itinerários formativos serão ofertados por cada estabelecimento de ensino e que, assim, em determinados municípios ou regiões próximas das suas residências, os estudantes não terão 
condições de escolherem que área seguir. Outra situação que mascara a suposta escolha dos estudantes é que o currículo do Ensino Médio será composto pela Base Nacional Comum Curricular (BNCC) e pelo itinerário formativo, no entanto o processo seletivo para acesso ao ensino superior considerará apenas as competências e as habilidades definidas na BNCC (Art. 5ํㅡ, Lei № 13.415/2017).

Em que pese aos aspectos problemáticos da $\mathrm{BNCC}^{12}$, no que se refere principalmente à visão fragmentada do conhecimento, bem como por invisibilizar as questões de gênero e orientação sexual e enfatizar o ensino religioso, muitos estudiosos da área da educação enfatizam veementemente que tal base aumentará ainda mais as discrepâncias entre o ensino público e privado. Assim, ao considerar apenas a BNCC para o processo seletivo de acesso ao ensino superior, a Lei № 13.415/2017 beneficia os estudantes das escolas privadas, considerando que o objetivo central dessas escolas é o acesso ao ensino superior e não há nenhuma restrição na oferta exclusiva das competências e habilidades da Base Nacional Comum Curricular. Pelo contrário, o artigo $4^{\circ}$, $\S 3^{\circ}$, dessa Lei prevê que, a critério dos sistemas de ensino, poderá ser composto itinerário formativo integrado, que se traduz na composição de componentes curriculares da BNCC e dos itinerários formativos. Isso pode ser aplicado pelas escolas privadas para atender a necessidade de preparar os estudantes para o Enem (Exame Nacional do Ensino Médio), principal porta de acesso ao ensino superior na atualidade.

No que diz respeito à oferta do itinerário da formação técnica e profissional, a lei que reformulou o ensino médio estabelece as chamadas parcerias para ofertada dos cursos, vejamos:

Art. 4: $\S 60$ A critério dos sistemas de ensino, a oferta de formação com ênfase técnica e profissional considerará:

I - a inclusão de vivências práticas de trabalho no setor produtivo ou em ambientes de simulação, estabelecendo parcerias e fazendo uso, quando aplicável, de instrumentos estabelecidos pela legislação sobre aprendizagem profissional;

§ 8 A oferta de formação técnica e profissional a que se refere o inciso $\mathrm{V}$ do caput, realizada na própria instituição ou em parceria com outras instituições, deverá ser aprovada previamente pelo

\footnotetext{
${ }^{12}$ Aprovada no dia 15 de dezembro de 2017, pelo Conselho Nacional de Educação (CNE) por 20 votos favoráveis e três contrários.
} 
Conselho Estadual de Educação, homologada pelo Secretário Estadual de Educação e certificada pelos sistemas de ensino.

$\S 11$. - Para efeito de cumprimento das exigências curriculares do ensino médio, os sistemas de ensino poderão reconhecer competências e firmar convênios com instituições de educação a distância com notório reconhecimento, mediante as seguintes formas de comprovação (BRASIL,2017, destaques nossos).

Essa perspectiva de denominadas parcerias para oferta da educação profissional já está em curso com o Pronatec, na sua versão do MedioTec, cujo vínculo com a reforma do ensino médio é apresentada em página eletrônica oficial do Governo ${ }^{13}$ :

O MedioTec é uma das novas ações do Governo Federal que funciona como uma forma de braço direito do Programa Nacional de Acesso ao Ensino Técnico e Emprego (Pronatec). A intenção do MedioTec 2017 é disponibilizar uma formação profissional e técnica de forma integrada aos ensinos básicos de ensino médio em tempo integral $O$ plano inicial é que o programa forneça um total de 82 mil vagas em todo o Brasil, de acordo com palavras do ministro da Educação e do presidente Michel Temer. O MedioTec nasce como uma tentativa de também acelerar o processo de mudanças que está em vigor na Medida Provisória 746/2016 medida esta que tem como objetivo uma reforma do ensino, principalmente médio, no país inteiro. A formação integrada, portanto, é uma tentativa de viabilizar exclusivamente para jovens alunos do ensino médio uma dupla certificação através dessa integração com o Pronatec 2017.

A meta do MedioTec para 2017, no que refere a atender 82 mil vagas, vem se a integralizar por meio de parcerias com as instituições privadas, institutos federais e o Sistema S, conforme apresentado na página eletrônica anteriormente citada.

É importante resgatarmos que, nessa dimensão da parceria públicoprivada, que caminha no sentido da privatização da educação, boa parte dos documentos publicados no Pronatec está relacionada à transferência de recursos para as instituições privadas.

Com isso, observamos que, no atual momento o Pronatec, por meio da oferta dos cursos técnicos com o MedioTec, ao invés da centralidade nos cursos FIC, o Programa está mais direcionado a beneficiar as empresas privadas,

\footnotetext{
${ }^{13}$ Disponível em: http://mediotec.pro.br/, acesso em: 15 de dezembro de 2017.
} 
pressupondo uma contribuição mais direta com a função de acumulação do Estado Capitalista. Constatamos isso tanto pela transferência dos recursos públicos para instituições que ofertam o MedioTec, como também pela natureza dos cursos técnicos estarem mais relacionados ao atendimento dos setores produtivos, do que os cursos FIC.

Como a pesquisa ainda está em andamento, entendemos que os dados da implementação do Programa, no que se refere principalmente às Instituições que ofertam o MedioTec e a base curricular dos cursos, fornecer-nos-ão respostas para as nossas hipóteses.

\section{Considerações gerais}

Não é forçoso enfatizar que a configuração, que vem assumindo a política de educação profissional no Brasil, com o Pronatec e com a Reforma do Ensino Médio, atende a lógica do contexto mundial, em que a educação, bem como os outros níveis ou dimensões da vida numa sociedade capitalista também termina sendo tratada, predominantemente, como uma mercadoria.

A título de considerações gerais, no que se refere ao apresentado pela Lei № 13.415/2017, refletimos que a separação por área de conhecimento não possibilita a formação integral dos estudantes, sobretudo na realidade brasileira em que a primeira etapa da educação básica é bastante frágil. Para além disso, a definição dos itinerários, a cargo dos sistemas de ensino, impossibilitará que os estudantes possam escolher a área de formação (ideia que foi vendida para justificar a reforma). O congelamento dos recursos públicos, por meio da Emenda Constitucional 95 (15/12/2016), que limita por 20 anos os gastos públicos, inviabilizam o funcionamento de escolas em tempo integral e também da ideia de melhoria da qualidade do ensino médio.

A Lei № 13.415/2017 apresenta vários caminhos para privatização do ensino profissional e gestão privada das escolas. Outros descompassos também são apresentados, mas não foram objeto de discussão nossa nesse momento, a exemplo de se estabelecer que profissionais com notório saber possam ministrar conteúdos de áreas afins à sua formação ou experiência profissional, além do envolvimento de Instituições a distância com notório conhecimento. 
Os fundamentos da Reforma do Ensino Médio são ancorados nas bases do Pronatec, e não é à toa que o Programa, com o MedioTec, está sendo anunciado pelo Governo como como uma tentativa de se acelerar o processo de mudanças da Lei № 13.415/2017.

Em suma, tanto o Pronatec como a Reforma do Ensino médio têm um projeto bem definido de contribuição para reprodução do sistema capitalista. A principal manifestação de cunho ideológico assenta-se no economicismo, a evidenciar o que aparece nos documentos e discursos oficiais da vinculação direta entre a política educacional e o desenvolvimento econômico. Desse modo, a concepção de educação é centrada na formação exclusivamente técnica em detrimento de uma formação capaz de possibilitar formação ampla, por meio da integração entre educação, trabalho, ciência e tecnologia. Portanto, evidenciamos uma maior acirramento da dualidade estrutural da educação nessa trajetória atual do programa.

\section{Referências}

ARAÚJO, Ronaldo Marcos de Lima. As novas "qualidades pessoais" requeridas pelo capital. Trabalho \& Educação, no 5, p. 18-33, 1999.

AZEVEDO, Joaquim. Ensino Profissional em Portugal, 1989-2014: Viagem da periferia para o centro das políticas educativas. In: Rodrigues, M. L. (Org). 40 anos de Políticas de Educação em Portugal. Edições Almedina, 2014.

BARRY, Brian \& RAE, Douglas W. Political evaluation. In: GREENSTEIN, F. \& POLSBY, N., ed. Handbook of politicai science. Reading, Addison-Wesley, 1975. v.1: Politicai scíence: scope and theory, p.337-40l.

BOURDIEU, Pierre. A ilusão biográfica. In: FERREIRA, Marieta de Morais; AMADO, Janaina. Usos e abusos da história oral. Rio de Janeiro: Editora da FGV, 1998.

BRASIL. Portaria MEC № 168 de 07/03/2013. Disponível em: https://www.legisweb.com.br/legislacao/?id=252083 Acesso em: 08 dez. 2017

Lei Federal $N^{\circ}$ 12513/11. Disponível em: https://presrepublica.jusbrasil.com.br/legislacao/1029688/lei-12513-11. Acesso em: 08 dez. 2017 
Medida Provisória (MP) 746/2016. Disponível em: https://www.congressonacional.leg.br/materias/medidas-provisorias/-/mpv/126992. Acesso em: 08 dez. 2017

Lei Federal № 13.415/2017. Disponível em: http://www.planalto.gov.br/ccivil 03/ ato2015-2018/2017/lei//13415.htm. Acesso em: 08 dez. 2017

BRAVERMAN, Harry. Trabalho e capital monopolista. Rio de Janeiro: Zahar, 1977.

CHESNAIS, François. A mundialização do capital. Tradução Silvana Finzi Foá São Paulo: Xamã, 1996.

COSTA, Frederico Lustosa da; CASTANHAR, José Cezar. Avaliação de programas públicos: desafios conceituais e metodológicos. Revista de Administração Pública, v.37, n.5, p.969-992, set./out. 2003

DOURADO, Luiz Fernandes (Org.). Plano Nacional de Educação (2011-2020): avaliação e perspectivas. Goiânia: Editora UFG; Belo Horizonte: Autêntica Editora, 2011.

DRAIBE, Sônia Miriam. Avaliação de implementação: esboço de uma metodologia de trabalho em políticas públicas. In: BARREIRA, Maria Cecília Roxo Nobre; Maria do Carmo Brant de CARVALHO (Org.). Tendências e perspectivas na avaliação de políticas e programas sociais. São Paulo: IEE/PUC-SP, 2001.

FERRETI, Celso João; SILVA, Mônica Ribeiro da. Reforma do ensino médio no contexto da Medida Provisória no 746/2016: estado, Currículo e disputas por hegemonia. Educ. Soc., Campinas, v. 38, №. 139, p.385-404, abr.-jun., 2017.

FIGUEIREDO, Marcus Faria; FIGUEIREDO, Argelina Maria Cheibub. Avaliação política e avaliação de políticas: um quadro de referência teórica. Análise \& Conjuntura, Belo Horizonte, v. 1, n. 3, set./dez. 1986.

GAMBOA, Sílvio Sánchez. A globalização e os desafios da educação no limiar do novo século. In: LOMBARDI, José Claudinei. (Org.). Globalização, Pósmodernidade e Educação: história, filosofia e temas transversais. Campinas: Associados, 2001.

HARVEY, David. A condição pós-moderna. São Paulo: Loyola. 1993.

JAMESON, Fredric. A cultura do dinheiro: ensaios sobre a globalização. Rio de Janeiro. Vozes. 2001.

KUENZER, Acácia Zeneida. Exclusão includente e inclusão excludente: a nova forma de dualidade estrutural que objetiva as novas relações de educação e trabalho. In: SAVIANI, D.; SANFELICE, J. L.; LOMBARDI, J. C. (orgs.). 
Capitalismo, trabalho e educação. 3. ed. Campinas: Autores Associados. p. 77-96, 2005.

MOURA, Dante Henrique. Ensino médio e educação profissional no Brasil nos anos 2000: movimentos contraditórios. In: MOURA, Dante Henrique, (org). Produção de conhecimento, políticas públicas e formação docente em educação profissional. 1 ed. - Campinas, SP: Mercado de Letras, 2013a.

; LIMA FILHO, Domingos Leite. A reforma do ensino médio regressão de direitos sociais. Revista Retratos da Escola, Brasília, v. 11, n. 20, p. 109-129, jan./jun. 2017. Disponível em: http://www.esforce.org.br/

O'CONNOR, James. USA, a crise do Estado capitalista. Rio de Janeiro: Paz e Terra, 1977.

RAMOS, M.N. O projeto unitário de ensino médio sob os princípios do trabalho, da ciência e da cultura. In: FRIGOTTO, G.; CIAVATTA, M.(Org.). Ensino médio: ciência, cultura e trabalho. Brasília, DF: MEC/SEMTEC, 2004. Disponível em: $<$ http://www.scielo.br/scielo.php?script=sci arttext\&pid=S198177462005000200002>. Acesso em: fev./2014.

RAVITCH, Diane. Vida e morte do grande sistema escolar americano: como os testes padronizados e o modelo de mercado ameaçam a educação. Porto Alegre: Sulina, 2011.

SCHEIRER, Mary Ann. Designing and using process evaluation. In J. S. Wholey, H. P. Hatry \& K. E. Newcomer (Eds.), Handbook of practical program evaluation. (pp. 40-68). San Francisco, CA: JosseyBass. Publishers, 1994.

SERVIÇO NACIONAL DE APRENDIZAGEM INDUSTRIAL. Panorama mundial da educação profissional: desafios e respostas. Brasília: SENAI, 2015.

SILVA, Danilma de Medeiros Silva. Desvelando o Pronatec: uma avaliação política do programa. 2015. 168f. Dissertação (Mestrado em Educação) - UFRN, Natal.

SOUZA, Lincoln Moraes de. Três ensaios sobre avaliação de políticas públicas. Natal: EDUFRN, 2014.

- O lugar da avaliação de politicas públicas no capitalismo organizado: o Estado supranacional e a avaliação. In: ARCOVERDE, Ana Cristina Brito. Avaliação de políticas públicas no capitalismo globalizado: para que e para quem? Recife: Editora UFPE, 2015.

WEISS, Carol H. Investigación evaluativa: métodos para determinar la eficiência de los programas de acción. México: Trilhas, 1978.

Recebido em: 28 de fevereiro de 2018.

Aprovado em: 01 de junho de 2018.

Publicado em: 21 de novembro de 2018. 